\title{
Internal Auditory Canal Meningioma
}

National Cancer Institute

\section{Source}

National Cancer Institute. Internal Auditory Canal Meningioma. NCI Thesaurus. Code C5307.

A meningioma that affects the internal auditory canal. 